\title{
The Bamboos of Blekinge: The Writing of Cultures in Swedish Proletarian Fiction
}

\author{
Paul Tenngart \\ Lund University, Lund, Sweden
}

\begin{abstract}
The national identity of the source culture often constitutes an important hermeneutic frame from which a translated text is understood. At the same time, literary texts themselves sometimes have a tendency to resist cultural narratives and stereotypical ideas of a certain nation. This article explores how such a resistance is made in the English translations of four Swedish novels from the 1930s. These novels are all central texts in the history of Swedish literature, as they form the very basis of a literary current that had a huge impact on the development of the Swedish welfare state-proletarian fiction. In the translations of Harry Martinson's, Moa Martinson’s, Eyvind Johnson's, and Ivar Lo-Johansson's breakthrough novels, the Anglophone target reader is faced with different kinds of disruptions of the Swedish national identity. Some of these disturb the conception of Sweden as a unified cultural space; others resist the idea of Sweden as a distinct cultural space. There is, however, no general rule to these disruptions: All four novels have their own, specific way of creating narrative resistance.
\end{abstract}

Keywords: Harry Martinson, Moa Martinson, Eyvind Johnson, Ivar Lo-Johansson, Swedish literature, proletarian literature, translation, national identity, cultural mobility, hybridity

\section{Introduction}

In her groundbreaking novel from 1933, Women and Appletrees, Swedish novelist Moa Martinson describes an ox-cart carrying a working-class family moving from the city to the countryside. The narrator reflects upon how an Englishman, German, Frenchman, or Bengalese would interpret the scene and concludes that the foreigner would misinterpret the moving party completely and get a wrong picture of Sweden and the Swedish working-classes:

He might have traveled back to England, Germany, France, or Bengal, and written in the big book of statistics bound in calfskin the following:

During a journey in Sweden in the year 1907, I found that the country's farm workers had an excellent economy. With a touching piety for his forefather's handmade cupboards and looms, a farm worker who moves owns three ox-carts filled with household furnishings. Farm workers' children in Sweden are wide awake and lively, and of that blonde and beautiful type, which is singular to the land in question.

Statistics are very undependable, but the Frenchman or German or Bengalese couldn't know, of course, that grandma was illegitimate, that the junk in the carts was hers and not the former paper worker's, now a farm worker, who got kicked

Paul Tenngart, Ph.D., Associate Professor, Centre for Languages and Literature, Lund University. 
out because he had been a member of a strike committee, or that Swedish children were more often dark and thin as gypsies, or that a farm worker in Sweden, in 1907, often didn’t have a bed to lie in. (Martinson, 1985, p. 31)

Moa Martinson couldn't have thought of the reader of the English translation of her novel; Women and Appletrees wasn't translated into English for another 50 years. But for the translation reader, the situation described in the novel offers a mirror. The foreign reader is this outsider looking into the affairs and conditions of a remote place. And Martinson's highlighting of the nation - the traveler journeys through "Sweden" and gets a notion of how "children in Sweden" are like-is equally true for the hermeneutic situation of the translation reader. Translational paratexts almost always put forth the national context of the work's origin. The foreign nation often emerges as an unavoidable frame from which the narrative is understood.

But Martinson isn't dealing with statistics. Statistics, she states in the novel, "make everything in life and literature into robots" (Martinson, 1985, p. 32). It is her duty as a novelist to enforce a literary resistance towards these shallow and stereotypical conceptions of a cultural location and its inhabitants. Moa Martinson's contrast between statistics and literature may very well be discussed in the words of Gabriele Schwab. In her Imaginary Ethnographies, Schwab stresses literature's task to form “creative disruptions” and instances of "perturbation” that resist hegemonic ideas and general conceptions (Schwab, 2012, pp. 3, 7). In writing literary narratives, novelists have the opportunity to "write culture" by rewriting cultural narratives:

I read a paradigmatic selection of literary texts as imaginary ethnographies, that is as texts that write culture by inventing a language that redraws the boundaries of imaginable worlds and by providing thick descriptions of the desires, fears, and fantasies that shape the imaginary lives and cultural encounters of invented protagonists. But imaginary ethnographies do more than write life stories; they also rewrite cultural narratives. (Schwab, 2012, p. 2)

How, then, is this disruptive writing of cultures made in literary narratives in relations to national identities? As we shall see, there are many different ways in which such a literary resistance can be made.

In this article, the four most central texts from the very influential literary current of which Women and Appletrees takes part, Swedish proletarian fiction, will be discussed. The central question will be how the English translations of these novels function as resistance towards the conception of the cultural identity of a nation. The novels are: Moa Martinson’s Women and Appletrees (Kvinnor och äppelträd), originally published in 1933 and translated by Margaret S. Lacy in 1985; Ivar Lo-Johansson's Breaking Free (Godnatt, jord!), originally published in 1933 and translated by Rochelle Wright in 1990; Eyvind Johnson's 1914 (Nu var det 1914), originally published in 1934 and translated by Mary Sandbach in 1970; and Harry Martinson's Flowering Nettle (Nässlorna blomma), originally published in 1935 and translated by Naomi Walford in 1936. These four novels, all appearing in Sweden during a period of two years, made a huge impact on Swedish literary history, both separately and jointly. They are all considered modern classics, and they represent quite a remarkable literary phenomenon - the common breakthrough of a generation of working-class authors at a time when the Swedish welfare state was beginning to take shape. Two of the authors were later to be awarded the Nobel Prize in Literature, Eyvind Johnson and Harry Martinson in 1974. The translations are, however, from different periods. Two of them are American (Women and Appletrees and Breaking Free), and two are British (1914 and Flowering Nettle).

In these novels, the national identity of Sweden is questioned in two principally different ways. The first has to do with the idea that a nation has an inner unity, and the second with the notion that a nation has a strong 
boundary towards the rest of the world. As we shall see, there is no general rule as to how the novels address these two aspects.

\section{Disrupting Unity}

Starting with the issue of unity, there are three different ways in which the texts create disruption. The idea of Sweden as a unified whole is confronted with three different kinds of diversity: regional, social, and ethnic.

Harry Martinson's Flowering Nettle is the most regionally rooted novel. A region in south-eastern Sweden gets a very distinct description and is depicted as a cultural location in its own right, strongly separated from other Swedish regions as well as from the national identity. When the protagonist, Martin, goes to school, for instance, the national institution is distinctly distinguished from the regional surroundings: "Inside the school was Sweden; and there the world was to be met with every day” (Martinson, 1936, p. 150). Emotionally, Martin doesn't live in Sweden but in the region. Everyday he has an opportunity to temporarily leave his cultural location and enter the national realm of school. In school he meets the "world", a complex and ambiguous word in the novel, signifying different geocultural locations. When an outsider appears in the region, he is described as being from another world: "He was not of this world; he was of Västergötland" (Martinson, 1936, p. 176). There are, then, many different worlds in the novel: Martin's region ("this world”) is one, other Swedish regions ("Västergötland") constitute other worlds, and Sweden (the world met with in school) composes yet another.

Dwelling upon his geocultural belonging, Martin shows a strong feeling of remoteness. His region is far away from the cultural centrality of the district around Stockholm:

This helped to strengthen an idea already formed in the children's minds, that all the grandest and best things lived in Uppland-why not God himself? Anyhow it seemed that all that was clear-cut, fine and sonorous came from there. Perhaps the children of Norrland and Bohuslän also kept their eyes turned towards the plains of Uppland. Very likely. All books, geography, nature-study, the catechism, "Swedes and their Rulers", and books about Indians-were written in Upplandish. Every one who came from Lake Mälar and Lake Hjalmar talked like books.

At school the children learned that their own province was called the garden of Sweden, but they would never believe it, for their spirit was a weather-vane pointing to Uppland superiority. (Martinson, 1936, p. 268)

Martin's remote region gets many names-it's called Blekinge, Göinge, and Lister, and sometimes it's named after its local nature and called "the heath". The identity of the region cannot be grasped with the administrative term for the particular county, Blekinge, grounded as it is in a national division of 24 Swedish districts. The varied ways of naming the region doesn't make its cultural identity ambiguous and vague, but rather enhances the impression that this location is of its own cultural kind.

Eyvind Johnson's 1914 is also regionally rooted. This novel takes place in northern Sweden, a location that is never given a name but is continually referred to as "up here", a place positioned as very remote from the southern parts of Sweden. The young protagonist, Olof, lies about his father, and his fellow timber-workers are impressed:

He used to help to build railways.

Oh, railways. Then he's from the south, of course. The ones who built the railways usually came from the south. Was he from far south? Doesn't he want to go back there, even though he's ill? He must want to go back there, all the same. It’s warm there, apples grow there. (Johnson, 1970, p. 41) 
It's warm in the south, in contrast to "up here”, where there's snow and darkness. The apples signify that in the south there is a different climate zone, a different flora, a different life. "I expect life's quite different down in the south to what it is here” (Johnson, 1970, p. 61), one of Olof's fellow workers says "with a hungry expression about his mouth" (Johnson, 1970, p. 61). Just like in Flowering Nettle, it is made clear that different Swedish regions constitute different worlds:

He was engaged to a girl from a town somewhere in the south, and at first he used to sit in the kitchen in the evenings and tell them about his young lady, what she said about this and that, what schools she had been to, how many dresses she had, how she spoke, how she did her hair. They listened with all their ears, their mouths open. (Johnson, 1970, p. 73)

It is not, though, a simple matter of north and south. There is a south and a far south, just like there is a north and a far north—and "up here” is the latter. Four geographical locations are thus put forward as culturally distinguished parts.

It's different in Women and Appletrees. Here, the contrast lies between two cities and an unnamed countryside, which is never given a distinct cultural character. Whereas Flowering Nettle and 1914 describe Sweden as regionally differentiated, Moa Martinson puts forward a social differentiation between the urban and the rural parts of the country. Before the working-class family decides to move from the city of Norrköping, a discussion takes place. The wife is reluctant:

What do you mean, do you think we can move to the country with an iron bed and an empty suitcase, to the country where folks have their places crammed with heaps of stuff? [...] And what will you do anyway? You can't be a farmhand; you can't even hold on to the reins. You've been at the factory your whole life. (Martinson, 1985, p. 17)

In geographical terms, the family doesn't move far, but socially life in the countryside is very different from city life, and working as a farmhand requires quite another set of laboring skills than factory work.

Adding to this impression of a social rather than a regional diversity, is the translator Margaret S. Lacy's decision to neutralize the use of dialect in Martinson's dialogue, and replace it with maintaining the Swedish colloquial word "ja" in italics throughout the novel. The text is thus perforated with this little Swedish word in italics, giving the novel a very colloquial and very strange impression. It is not, though, a regional impression. In a note on the translation, the use of the "ja" is explained as an attempt to translate the "sing-song music" of the Swedish language. (Martinson, 1985, p. 200)

This impression is even stronger in Ivar Lo-Johansson's Breaking Free. In this novel about rural estate-workers, the region is remarkably anonymous, with no cultural identity whatsoever. On the contrary, the region in which all the characters live is described as identical with all other Swedish estates. The estate-workers move from estate to estate, between similar milieus, making any cultural specificity impossible. The workers have no roots: “There was something odd about the old estate-workers' situation. They'd always been without roots, with the dew of many autumn moving days in their hair...” (Lo-Johansson, 1990, p. 419). Socially, the workers are described as a distinct, separated rural class, but geographically this vernacular is nationwide. “'D’you want to change baron's with me, maybe?', one of them asks and gets the answer: 'One baron's as good as the next, but I'll give ten kronor for a change of pace!’” (Lo-Johansson, 1990, p. 32). It doesn't matter who they work for or where they live. Moving to another part of Sweden is just a change of pace, not of place. 
Lo-Johansson's estate-workers aren't emotionally and culturally remote from other rural parts of the country, but they are far, far away from the city. " 'Tell us something from the city', they ask one of the few people who have been there. They long for this distant place: 'In the city there aren’t any estate-workers!'” (Lo-Johansson, 1990, p. 135) they cry. But they know that this longing is vain:

"We'll never get there..."

"What would you do in the city, if you don't mind my asking?"

"If only a person could get ahead enough to take over a croft before it’s too late”, says Göranson. "That would be a step in the right direction".

“The city’s a dream, but a croft is partway there”, add others. (Lo-Johansson, 1990, p. 135)

The workers and their families are stuck in their rural class, devoid of cultural and regional character. They will never break free. The translator Rochelle Wright's ethnographic endnotes on the Swedish social and economical system at the time, add to this impression of a nationwide class of agrarian workers, fundamentally separated from urban life.

This difference between highlighting regional or social roots creates different ways to describe human agency. In Flowering Nettle and 1914, where characters are predominantly regionally rooted, human agency is first and foremost of a cultural kind: Different groups of people within Sweden have different levels of cultural capital, different cultural positions, and different aims. In Women and Appletrees and Breaking Free, on the other hand, human resources, positions and aims are mostly social. There are, however, also differences to be found within these two categories. Flowering Nettle and Breaking Free are both unambiguous: There is no real social agency described in the former and no cultural agency in the latter. 1914 and Women and Appletrees are less clear-cut. The lack of geocultural place names and the description of interregional social milieus in 1914, infer a tendency towards social agency existing side by side with the dominant cultural agency, and in Women and Appletrees one culturally specific region is described. Even if this region (Mark in western Sweden) is peripheral in the novel's narrative, it marks the existence of cultural agency.

When it comes to ethnic differentiation, there are a couple of identities within Sweden to be found in each of the four novels. In 1914, Sami (called "Lappish" in the novel) and Finnish people are described as living in the country. In Breaking Free, Romani (called “Gypsy”), Jewish and Italian characters appear, and in Women and Appletrees, there are Romani (“Gyspy”), French, Jewish, and Walloon identities. The highest degree of ethnic differentiation appears in Flowering Nettle, where there are Romani (“Gyspsy”), American, Herulian, Wendish, Willandian, and Danish identities within Sweden. Additionally, a special local group called "basket-makers” is also described as a specific ethnic identity:

People, homeless from choice, wandered from the basket-makers' cabins to sit in the thickets and listen. There were old women in kerchiefs; old basket-plaiters who had spent more than half their lives in Pomerania. Their speech, a blend of the dialect of the heath villages and low Pomeranian, sounded Wendish. There were many who could not understand it. But the old women in their Pomeranian shawls gathered together like witches on the moor, where the heather path vanished into Göinge. (Martinson, 1936, p. 276)

This people have common international experiences from Pomerania in northern Germany. Compared to other Swedes, they dress differently, speak differently and act differently. There is no equivalent to these basket-makers in any of the other novels, which illustrates that Flowering Nettle stands out in this material, not 
only in its thick regional descriptions but also in the way the colorfully depicted local vernacular creates a specific regional ethnicity.

\section{Disrupting Boundary}

How do these novels, then, disrupt the idea of the nation as a distinct, limited sphere? Well, for the translation reader I would say that the boundary of the nation is disrupted every time a foreign location is mentioned, thereby pointing out the fact that human thinking, acting, and narrating is not nationally limited. Recognizing all the international elements in a literary material is a simple method (and by no means the only one) to identify its thematic relation to what Stephen Greenblatt calls "cultural mobility", "the often unpredictable movements of texts, ideas, and whole cultures" (Greenblatt, 2010, p. 7). Merely listing the foreign locations mentioned in the novels, gives us an idea of different degrees of thematic cultural mobility.

In Eyvind Johnson's 1914, there are very few direct associations to foreign places and identities. All non-Swedish locations referred to in any way throughout the novel are Europe, Finland, Norway, Germany, Bohemia, France, Russia, America, and Africa. Two of these are Nordic countries and five are European locations. Only two are locations outside Europe, and both of these are very broad and unspecific.

In Moa Martinson’s Women and Appletrees, there are much more foreign associations: abroad, Scandinavia, Denmark, Norway, the North Atlantic, Europe, France, Paris, Flanders, the Ardennes, Great Britain, Germany, Poland, Russia, Italy, Florence, America, Utah, Palestine, Arabia, Mongolia, and the Orient. Compared to Johnson's novel, more locations outside Europe are mentioned, and the European associations are more specific.

A similar amount of international connections is to be found in Ivar Lo-Johansson's Breaking Free. The foreign locations mentioned or referred to are: abroad, the World, Scandinavia, Norway, Finland, Iceland, Europe, Great Britain, Germany, France, Belgium, Russia, Italy, Rome, the Dead Sea, Palestine, the Orient, Turkey, Africa, Samarkand, Australia, and America.

In Moa Martinson's and Lo-Johansson's novels, then, life in Sweden is less nationally limited than in Johnson's. To a higher degree than in 1914, the narrators and characters in Women and Appletees and Breaking Free act, talk, think, and narrate with the world outside the Swedish borders in mind. Compared to Harry Martinson's Flowering Nettle, however, all three novels appear nationally limited. These are the foreign locations directly mentioned by Harry Martinson's narrator and characters: abroad, the World, Scandinavia, Northern Europe, Denmark, Smøgen, Norway, Snehætten, Finland, Iceland, Germany, Pomerania, Prussia, Schleswig, Bavaria, Straal, Bremen, Nuremberg, Holland, England, Essex, London, Hull, Cambridge, the Somme, Macedonia, Greece, Lombardia, Castilia, America, California, Florida, Minnesota, Utah, Missouri, Portland, New York, Chicago, St. Louis, Tampa, Sacramento River, Sacramento Valley, Indian River, the Rocky Mountains, Columbia, Mexico, Africa, Kilimandjaro, the Congo River, Nazareth, Babylonia, Babel River, the Orient, India, Madras, Punjab, China, the Himalayas, Japan, Malacca, Australasia, Australia, Sydney, Wooloomooloo, Tasmania, New Zealand, Wellington, Siberia, the Ob, and the Jenisej.

The novel is full of international references, making the characters and milieu depicted very internationally influenced. Here, Sweden is a place where people are human beings living in the world rather than citizens living in a specific country.

So, a pattern of differences has emerged, but merely listing these foreign references is to stop at what Moa 
Martinson rejects as statistics. And she's right: This kind of quantitative information tends to reduce the complexity involved. We need to dig deeper into the international elements and analyze what they are and what they do.

First of all, when we are dealing with translations, these foreign associations are typically read by a culturally distant reader. Depending on this reader's cultural background, different elements listed above work differently. For the American and British readers, most of the associations are Swedish connections to different international locations viewed from a third cultural place. There is, then, a double perspective involved: The American readers, for example, look at the Swedish character looking at the world. In some instances, however, the Swedish characters look at American and British geocultural locations. Here, a mirroring effect takes place: The American readers look at a Swedish character looking at America. The reader looks at him or herself through the eyes of the other. These are quite complex hermeneutic operations that need to be studied closely.

Secondly, the lists above don't account for the issue of frequency. Some of these international associations are made only once, others are made often. In Flowering Nettle, for example, California is mentioned many times, since that's where the child protagonist, Martin, thinks his mother has emigrated to. Longing for his mother, Martin evokes the idea of the American state on many pages, thus making the impact of California in the novel far stronger than, say, the impact of Utah in Women and Appletrees.

Thirdly, just a quick glance at the elements listed reveals that they constitute very different geocultural categories. There are broad, general concepts like "the World" and "abroad”, and a bit more specific but still quite general concepts like "the Orient” and "Northern Europe". There are continents, nations, and states, and there are regions, cities, and city districts (Wooloomooloo in Sydney). There are also natural categories like islands, rivers, and mountains. In order to have a substantial idea of what these associations tell us about the way the narrators and characters are positioned in the world, we need to distinguish between these categories and acknowledge that they work differently.

Another crucial difference between these international elements has to do with the ways in which they appear in the novels. Some of them are results of actual international experiences, when a character is born abroad or has traveled to other countries. Others have to do with foreign things or products: money, food, tools, machines, paintings, and the like. These categories of cultural mobility are both physical, and they need to be distinguished from a more mental appearance of foreignness when characters think about other locations and cultures. These thoughts of the world are sometimes accurate and sometimes distinctly based on misconceptions, and they appear in fantasies, longings, dreams, children's games, philosophical or existential musings, and in reading fiction, non-fiction, or newspapers. Another category of international elements only occurs in the narration, when the narrator gives an international perspective on vernacular Swedish phenomena or when he or she makes use of an internationally based imagery. Occasionally, it is difficult to know whether the international connection is made solely by the narrator or also by the character, especially when it is unclear if the narration uses free indirect speech or not, which is often the case in Flowering Nettle. Needless to say, foreign connections work very differently depending on where and how they appear in the text.

Furthermore, international associations may have very different functions in the texts. In my material, there is a strong contrast between two oppositional ways in which the foreign elements are used to signify the relation between the Swedish vernacular and the international realm invoked. On the one hand, these elements can 
construct an impression of cultural hybridity between the Swedish "here” and the foreign "there”. This happens a lot in Flowering Nettle, for example when the basket-makers' speech is described as "a blend of the dialect of the heath villages and low Pomeranian” (Martinson, 1936, p. 276). The local dialect of the villages merges with the German dialect into a hybrid speech. Such an hybridity also occurs mentally in the way the narrator or the characters think about the world, for example when the local footwear, "red alderwood clogs", is said to look like “the poorest houseboats on the rivers of China” (Martinson, 1936, p. 50), or when hazel is described as "the bamboos of Blekinge” (Martinson, 1936, p. 172). The cultural and natural location of the province of Blekinge is not viewed as a singular, isolated space, nor as variant of the national Swedish culture and nature, but as a place in the world with relations to any other place all over the globe.

On the other hand, foreign elements can be used to create distance between the local and the international, thus confirming rather than disrupting the national boundary. This effect is evident when the narrators in Breaking Free and 1914 refer to World War I, a war in which Sweden did not take part. In Lo-Johansson's novel, the reader is told that the war reached the Swedish estate "as a mere echo". To the estate-workers, "the affairs of the world were far away”. One of the main characters, we are told, “doesn't pay any attention to strikes and wars, he just plows” (Lo-Johansson, 1990, p. 448). In 1914, the timber-workers show very mild reactions to the on-going war: "One would say languidly that Germany was going to win, another equally languidly, that France or Russia would win, but that it was good, or bloody awful, that the weather was so warm” (Johnson, 1970, p. 92). The war in central Europe doesn't really have anything do to with them. It's far more important how the local weather is like. The distance between international politics and the conditions for rural laborers in northern Sweden is poignantly expressed when Johnson describes how his protagonist gets hold of news from the war:

Olof began to understand in earnest that far-away armies had clashed in a duel of thundering artillery. Fragments of newspaper found their way by curious routes out to the potato field; scraps from the latrine and wrappings that the autumn wind had taken charge of. He picked up lumps of wet paper, sticky with mud, smoothed them out and read. (Johnson, 1970, p. 101)

Confined to his autumn potato field, Olof is very remote from the big world out there, in striking contrast to Harry Martinson's Martin, who experiences bamboos in the local hazel woods and meets China in the alderwood clogs of the Blekinge people. Even though international elements principally constitute a kind of cultural mobility, they sometimes create, in effect, the opposite impression-that of cultural remoteness and isolation.

Lastly, international connections can be made either with or without the nation as a cultural frame through which the international association is filtered. International elements may, for example, be mediated to the local vernacular by the national institution of school or through national newspapers. In Breaking Free, for instance, it is made quite clear that the children's knowledge of the world is learned in school, and that knowledge of the nation is more important than knowledge of foreign countries:

Some rolled-up maps standing in a holder by the wall looked like big horns. The map of the world was outermost. It was only taken out a couple of times each term. The map of Sweden was nearly worn out and both ends were frayed, like a coarse brush. (Lo-Johansson, 1990, p. 233)

National knowledge forms the basis for the children's understandings of the world. Knowledge of the rest of the globe is then added, occasionally, on to this national frame. The leader of the estate, Baron von Spax, also 
makes it clear that the estate-workers first and foremost are citizens of Sweden, and that the customs of the estate belong to national traditions. The harvest feast on the estate is compared to similar feasts in France, but von Spax insists that their custom has "deep, truly Swedish origins" (Lo-Johansson, 1990, p. 174). The likeness to the French feasts is just a random similarity, constituting no real relation between the local custom and the foreign culture.

When international elements occur in the local without being filtered through the national frame, the question of boundary is connected to the question of unity. These direct connections between the local vernacular and foreign locations are primarily made in the most regionally rooted novel, Harry Martinson's Flowering Nettle. Here, the lack of national importance to local customs and thinking is sometimes directly expressed, for example when the link between the region and Pomerania is pointed out: "But Pomerania was something different; it had been their work-country. Apart from that even Växjö was far, far distant. Of Stockholm they dared hardly think; America itself was almost nearer" (Martinson, 1936, p. 50).

For the local people, the German region of Pomerania is closer than Växjö, a town in the neighboring district of Småland. Pomerania is not geographically closer, of course, but emotionally and culturally. And the capital of Sweden, Stockholm, is very far away. The people of the region have "almost" stronger cultural ties to America than to the center of the nation. But the local region is not only connected to Pomerania, far from it. For the young protagonist, Blekinge takes part in the world in a way that ignores national borders:

With it came the thought that Tyra was lovely, but at the moment of saying, "Yes, there are lots of lovely things", he had thought of the whole world: of water-lilies, of Columbia in geography, and Ob and Jenisej-gazelles which ran about Africa like the roe-deer in the Crown Forests in Harasjö. (Martinson, 1936, p. 261)

Martin's immediate surroundings-his friend Tyra, the water-lilies, the roe-deer and the forest of Harasjö — are linked to a variety of very different African, Asian, and American locations being merged into an idea of "the whole world". And the "here" of Harasjö is a part of that common, global frame. Martin, Harasjö, and Blekinge belong to the world, not to any administrative or political entity.

If we compare the four novels more generally as to how they use international elements, we can conclude that Harry Martinson's Flowering Nettle contains many international associations, most of which create an impression of hybridity between the local culture and foreign locations. Furthermore, the national frame of Sweden and Swedishness is generally described as non-important for local lives. Moa Martinson's Women and Appletrees does not contain as many foreign elements as Flowering Nettle, but quite a few. More often than not, these create hybridity rather than distance between the local vernacular and the international locations. When it comes to the question of a national frame, the importance of Sweden and Swedishness is neither rejected nor reinforced. In Ivar Lo-Johansson's Breaking Free, there are as many international associations as in Moa Martinson's novel, but these create an impression of cultural distance rather than hybridity, and the national frame of Sweden is reinforced. Eyvind Johnson's 1914, then, contains very few international connections, and those which do appear create distance between the local vernacular of northern Sweden and the world outside the national border, giving the region a distinct impression of remoteness. On the other hand, the national frame is not reinforced, as it is in Breaking Free, but avoided. Then, the nation does not appear as an important cultural entity. 


\section{Conclusion}

The idea of a unified and separated nation is difficult to avoid when presenting a translated literary text to the target culture reader. As a result of this, the national identity of the source culture becomes an important hermeneutic frame from which the translated text is understood. The literary texts themselves, however, often offer resistance towards shallow and stereotypical notions of national identities, and this can be done in a multitude of ways. The four novels discussed in this article-Moa Martinson's Women and Appletrees, Ivar Lo-Johansson’s Breaking Free, Eyvind Johnson’s 1914, and Harry Martinson’s Flowering Nettle-illustrate four different ways to disrupt a general conception of national belonging. In Women and Appletrees, the idea of the nation as a unified whole is disrupted in depicting Sweden as a socially and ethnically differentiated cultural space, and the idea that the nation constitutes a distinct, limited sphere is disturbed by creating impressions of hybridity between local and international phenomena. In Breaking Free, the idea of national unity is disrupted socially and ethnically, but the novel offers no real disturbance of the idea of national boundary. In 1914, national unity is disrupted socially, ethnically, and regionally, but there is no distinct disturbance of national boundary. Flowering Nettle is the most disruptive of the four novels. Here, the idea of a national Swedish unity is disrupted ethnically and regionally, and the idea of Sweden as a limited, cultural realm is disturbed both by creating hybridity and by rejecting the importance of a national frame.

\section{References}

Greenblatt, S. (2010). Cultural mobility: an introduction. In S. Greenblatt et al (Eds.), Cultural mobility: a manifesto. Cambridge, MA: Cambridge University Press.

Johnson, E. (1934). Nu var det 1914 (It was now 1914). Stockholm: Bonniers.

Johnson, E. (1970). 1914. (M. Sandbach, Trans.). London: Adam Books.

Lo-Johansson, I. (1933). Godnatt, jord! (Good night, earth!). Stockholm: Bonniers.

Lo-Johansson, I. (1990). Breaking free. (R. Wright, Trans.). Lincoln, NE, and London: University of Nebraska Press.

Martinson, H. (1935). Nässlorna blomma (The nettles are in bloom). Stockholm: Bonniers.

Martinson, H. (1936). Flowering nettle. London: Cresset Press.

Martinson, M. (1933). Kvinnor och äppelträd (Women and appletrees). Stockholm: Bonniers.

Martinson, M. (1985). Women and appletrees. (M. S. Lacy, Trans.). New York: Feminist Press.

Schwab, G. (2012). Imaginary etnographies: Literature, culture, \& subjectivity. New York: Columbia University Press. 